\title{
Gender and Spatial Disparities of Suicide Mortality Risk in Kermanshah Province, Iran: A Brief Report
}

\author{
Mehran Rostami ${ }^{1}$, Abdollah Jalilian ${ }^{2}$, Shahab Rezaeian ${ }^{3, *}$, Artin Kamali ${ }^{4}$ \\ ${ }^{1}$ Deputy for Treatment, Kermanshah University of Medical Sciences, Kermanshah, Iran \\ ${ }^{2}$ Department of Statistics, Razi University, Kermanshah, Iran \\ ${ }^{3}$ Infectious Diseases Research Center, Kermanshah University of Medical Sciences, Kermanshah, Iran \\ ${ }^{4}$ Director-General of Forensic Medicine Organization, Kermanshah, Iran
}

\begin{abstract}
ARTICLE INFO
Article History

Received 22 June 2019

Accepted 14 August 2019

Keywords

Suicide

mortality

ecological study

Iran

(C) 2019 Dr. Sulaiman Al Habib Medical Group. Publishing services by Atlantis Press International B.V. This is an open access article distributed under the CC BY-NC 4.0 license (http://creativecommons.org/licenses/by-nc/4.0/).
\end{abstract}

\section{INTRODUCTION}

In Iran, the estimated rate of complete suicide (2006-10) was about five per 100,000 population [1]. Several sociodemographic and economic factors (such as average household expenditure, unemployment rate, and divorce rate) were positively associated with suicide mortality [2]. In addition, marital problems and family conflicts are the two well-known familial risk factors for suicide [3]. Iran's western provinces have a higher suicide rate compared to the other provinces in the country [1,4]. In addition, Kermanshah province has a noticeably higher suicide rate compared to the national average [1,5]. A previous study conducted in Kermanshah has also reported multiple individual level factors associated with the risk of attempted or completed suicide [6]. Determining the temporal and seasonal patterns of disease helps identify different spatial patterns over time and improve our understanding of the risk factors affecting the distribution of disease and death across the population and set them in the form of geographical maps [5,7]. Meanwhile, a previous ecological study has been conducted to visualize spatial heterogeneity in suicide mortality risk across the counties of the province [8]. Therefore, to improve preventive measures, a better understanding of the distribution of suicide at the national and subnational levels is important. So, the aim of this study is to update spatial variations in the risk of complete suicide across the counties of Kermanshah province, the most populated western province of Iran.

"Corresponding author. Email: shahab.rezayan@gmail.com Peer review under responsibility of the Dr. Sulaiman Al Habib Medical Services Group Company

\section{MATERIALS AND METHODS}

\subsection{Study Population}

Kermanshah province is among the provinces with low socioeconomic status. Based on the 2016 Census of Population and Housing, the province's population was $1,952,434$ (about $2.5 \%$ of the total Iranian population) with an estimated unemployment rate of 22\% in 2016. This province is composed of 14 counties (Kermanshah, Qasr-e Shirin, Islamabad-e Gharb, Sahneh, Sonqor, Sarpol-e Zahab, SalasBabajani, Ravansar, Dallahoo, Gilan-e Gharb, Javanrud, Kangavar, Harsin, and Paveh) and has a total land area of about $25,009 \mathrm{~km}^{2}$ [9]. The capital of Kermanshah province is the city of Kermanshah.

\subsection{Data Collection and Data Analysis}

In this study, county-level counts of suicide deaths in Kermanshah province were obtained from the dataset provided by the provincial Forensic Medicine Organization (FMO). Death certificates issued by the FMO have been accepted as a valid mortality data source for epidemiologic studies of suicide $[4-7,10]$. The corresponding populations of counties are obtained from the 2016 national census of population and housing [11]. We applied an appropriate Bayesian spatial approach-Besag, York and Mollie (BYM) model-to model the status of complete suicide in the Kermanshah province over a 1-year period, from March 21, 2016 to March 20, 2017. The BYM model, the most commonly used Bayesian model in spatial disease mapping, can be used for computing relative risk, with and without 
Table 1 The observed $\left(Y_{i}\right)$ and estimated expected $\left(\hat{E}_{i}\right)$ number of cases of complete suicide in each county of Kermanshah province, from March 2016 to March 2017, for males, females, and both sexes combined. The corresponding populations $\left(n_{i}\right)$ of counties are obtained from the 2016 national census of population and housing

\begin{tabular}{|c|c|c|c|c|c|c|c|c|c|}
\hline \multirow{2}{*}{ County } & \multicolumn{3}{|c|}{ All } & \multicolumn{3}{|c|}{ Men } & \multicolumn{3}{|c|}{ Women } \\
\hline & $Y_{i}$ & $\boldsymbol{n}_{i}$ & $\hat{E}_{i}$ & $Y_{i}$ & $n_{i}$ & $\hat{E}_{i}$ & $Y_{i}$ & $n_{i}$ & $\hat{E}_{i}$ \\
\hline Kermanshah & 151 & 925,962 & 146.32 & 102 & 465,624 & 94.28 & 49 & 460,338 & 51.99 \\
\hline Islamabad-e Gharb & 22 & 120,094 & 18.98 & 16 & 60,702 & 12.29 & 6 & 59,392 & 6.71 \\
\hline Dallahoo & 13 & 30,803 & 4.87 & 8 & 15,208 & 3.08 & 5 & 15,595 & 1.76 \\
\hline Gilan-e Gharb & 13 & 49,561 & 7.83 & 3 & 25,024 & 5.07 & 10 & 24,537 & 2.77 \\
\hline Kangavar & 11 & 64,613 & 10.22 & 8 & 32,363 & 6.55 & 3 & 32,250 & 3.64 \\
\hline Sonqor & 11 & 69,876 & 11.04 & 8 & 34,998 & 7.09 & 3 & 34,878 & 3.94 \\
\hline Harsin & 9 & 65,261 & 10.31 & 4 & 32,791 & 6.64 & 5 & 32,470 & 3.67 \\
\hline Sarpol-e Zahab & 9 & 71,316 & 11.27 & 4 & 35,599 & 7.21 & 5 & 35,717 & 4.03 \\
\hline Qasr-e Shirin & 6 & 20,020 & 3.16 & 5 & 10,660 & 2.16 & 1 & 9360 & 1.06 \\
\hline Salas-Babajani & 5 & 28,504 & 4.50 & 2 & 14,550 & 2.95 & 3 & 13,954 & 1.58 \\
\hline Javanrud & 5 & 61,385 & 9.70 & 2 & 31,193 & 6.32 & 3 & 30,192 & 3.41 \\
\hline Ravansar & 3 & 39,571 & 6.25 & 3 & 20,225 & 4.10 & 0 & 19,346 & 2.18 \\
\hline Sahneh & 3 & 60,580 & 9.57 & 3 & 30,281 & 6.13 & 0 & 30,299 & 3.42 \\
\hline Paveh & 1 & 50,464 & 7.97 & 1 & 25,408 & 5.14 & 0 & 25,056 & 2.83 \\
\hline Total & 262 & $1,658,010$ & 261.99 & 169 & 834,626 & 169.01 & 93 & 823,384 & 92.99 \\
\hline
\end{tabular}

adjusting for independent variables (risk factors). This Bayesian model takes spatial proximity into account in the calculation of spatial risk which is widely used in epidemiology. The BYM model is one of the best choices in ecological analysis compared to other Bayesian ecological models for mapping spatial risk. Moreover, the BYM model outputs provide a map of population-adjusted relative risk [12]. This Bayesian spatial approach was fitted to make inference about the relative risk of complete suicide across the counties of the province. The model details and its application to suicide mapping have been described elsewhere $[5,13]$. All analyses were performed at the 0.05 significance levels using $\mathrm{R}$ package.

\subsection{Ethical and Legal Considerations}

Private information of deceased individuals who committed suicide was not used in the study; thus, informed consent was not required as the data are published in the public domain. The research protocol was reviewed and approved by the Ethics Committee of Kermanshah University of Medical Sciences in Iran (no. IR.KUMS.REC.1396.337).

\section{RESULTS AND DISCUSSION}

A total of 262 complete suicide cases were registered, with age ranging from 10 to 89 years, during the selected period. As shown in Table 1, the observed and estimated expected number of the complete suicide cases in each county of Kermanshah province for males, females, and all persons were calculated. Based on this calculation, Figure 1 shows the map of posterior mean of the county-specific relative risk. Demonstration of spatial (geographical) distributions enables the visual display of disparities within designated geographical areas. It can be seen that for all individuals, Dallahoo, Gilan-e Gharb, and Qasr-e Shirin are counties with high relative risk; also Paveh, Javanrud, and Ravansar fall into the low relative risk category. For females, Paveh, Sahneh, Sonqor, and Kangavar fall into the low relative risk category; moreover, Gilan-e Gharb is a county with high relative risk. For males, Paveh and Javanrud fall into the low relative risk category. This map reveals gender and spatial disparities in the suicide mortality relative

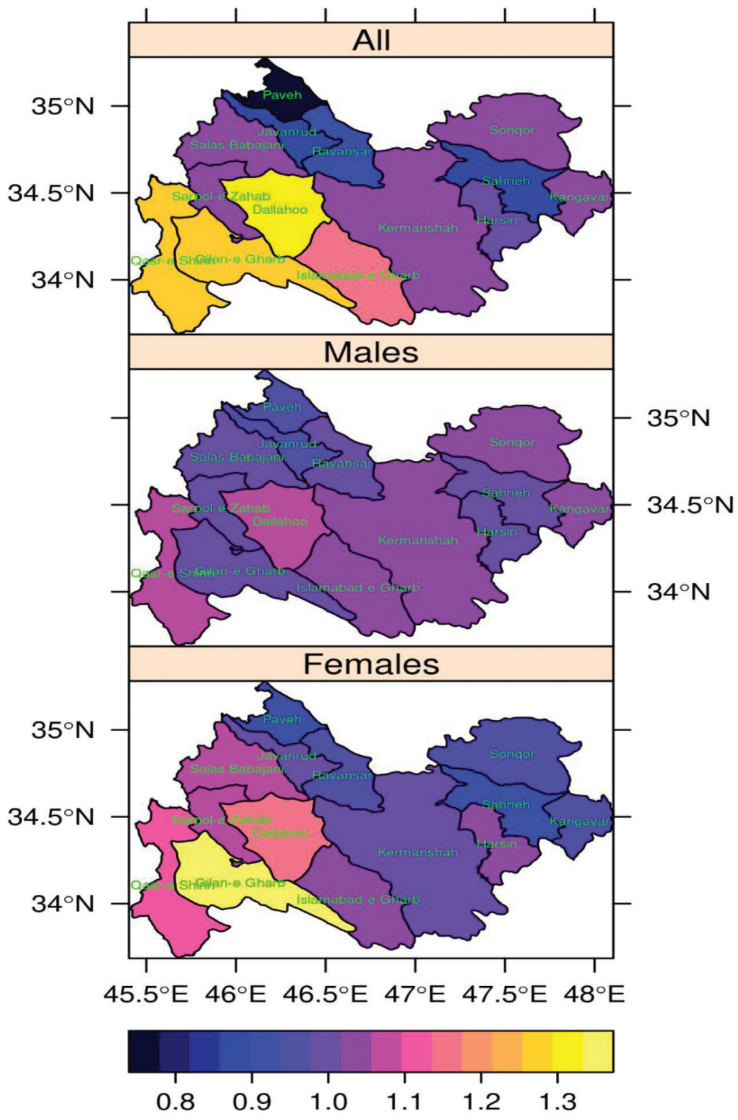

Figure 1 Posterior mean of the county-specific relative risk of complete suicide in the counties of Kermanshah province, compared to the risk level for the whole province, from March 2016 to March 2017.

risk in the county level, although it was not statistically significant. This finding is in line with past findings from studies that were conducted from 2006 to 2011 [5]. Findings from this study can be used to aid priority setting for suicide prevention interventions. In terms of the Human Development Index (HDI) [13], Iran ranks 60th among 189 countries in 2018. In Iran, the HDI was 0.834 for 
men and 0.726 for women [14]. This difference can be effective in justifying gender inequality in the distribution of suicide-related mortalities.

Owing to the unavailability of data, we included 1 year of data in our analysis. Therefore, we ended up with a small sample size, which might have influenced the statistical significance of results. Some major influential factors such as mental health problems (major depressive disorders, mood and anxiety disorders, substance use disorders), and socioeconomic characteristics were not included in this study, because the related dataset has not been provided by the FMO. These factors were basic requirement data for designing suicide prevention interventions. Previous studies show that majority of suicide victims have committed suicide using violent methods in this province $[5,6,10]$. In conclusion, this short report presents an evidence of gender and spatial (geographical) heterogeneity in suicide mortality risk in the county level in a high incidence province of Iran. It is beyond the scope of this report to discuss the possible causes of this heterogeneity; thus, further research is warranted to gain a better understanding as well as to illustrate the factors associated with gender and spatial disparities of suicide mortality risk over a longer period.

\section{CONFLICTS OF INTEREST}

The authors declare they have no conflicts of interest.

\section{AUTHORS' CONTRIBUTION}

$\mathrm{MR}, \mathrm{AJ}$ and SR participated in literature review, data analysis, and wrote the manuscript. AK were involved in data collection, and data entry. All of the authors performed step-by-step follow-up and reviewed and revised the whole paper.

\section{ACKNOWLEDGMENTS}

This study was financial supported by the Research Council of Kermanshah University of Medical Sciences (Grant Number: 96332).

\section{REFERENCES}

[1] Kiadaliri AA, Saadat S, Shahnavazi H, Haghparast-Bidgoli H. Overall, gender and social inequalities in suicide mortality in
Iran, 2006-2010: a time trend province-level study. BMJ Open 2014;4:e005227.

[2] Haghparast-Bidgoli H, Rinaldi G, Shahnavazi H, Bouraghi H, Kiadaliri AA. Socio-demographic and economics factors associated with suicide mortality in Iran, 2001-2010: application of a decomposition model. Int J Equity Health 2018;17:e77.

[3] Nazarzadeh M, Bidel Z, Ayubi E, Asadollahi K, Carson KV, Sayehmiri K. Determination of the social related factors of suicide in Iran: a systematic review and meta-analysis. BMC Public Health 2013;13:4.

[4] Nazari Kangavari H, Shojaei A, Hashemi Nazari SS. Suicide mortality trends in four provinces of Iran with the highest mortality, from 2006-2016. J Res Health Sci 2017;17:e00382.

[5] Rostami M, Jalilian A, Rezaei-Zangeneh R, Jamshidi T, Rezaeian M. Suicide pattern in Kermanshah province, West of Iran: March 2012-March 2013. Middle East J Fam Med 2016;14:38-48.

[6] Poorolajal J, Rostami M, Mahjub H, Esmailnasab N. Completed suicide and associated risk factors: a six-year population based survey. Arch Iran Med 2015;18:39-43.

[7] Rostami M, Jalilian A, Poorolajal J, Mahaki B. Time series analysis of monthly suicide rates in West of Iran, 2006-2013. Int J Prev Med 2019;10:78.

[8] Rostami M, Jalilian A, Ghasemi S, Kamali A. Suicide mortality risk in Kermanshah Province, Iran: a county-level spatial analysis. Epidemiol Biostat Public Health 2016;13:e11829-7.

[9] Statistical Center of Iran. Iranian population and housing census. Statistical Center of Iran, Tehran; 2016. Available from: https://www.amar.org.ir/english/Iran-at-a-glance/Kermanshah (accessed June 2018).

[10] Rostami M, Jalilian A, Rezaei-Zangeneh R, Salari A. Factors associated with the choice of suicide method in Kermanshah Province, Iran. Ann Saudi Med 2016;36:7-16.

[11] Statistical Center of Iran. 2016 Iranian population and housing censuses. Statistical Center of Iran, Tehran; 2017. Available from: https://www.amar.org.ir/english/Population-and-HousingCensuses (accessed May 2018).

[12] Riebler A, Sørbye SH, Simpson D, Rue H. An intuitive Bayesian spatial model for disease mapping that accounts for scaling. Stat Methods Med Res 2016;25:1145-65.

[13] Mahaki B, Mehrabi Y, Kavousi A, Mohammadian Y, Kargar M. Applying and comparing empirical and full Bayesian models in study of evaluating relative risk of suicide among counties of Ilam province. J Educ Health Promot 2015;4:50.

[14] United Nations Development Programme. Human development indices and indicators: 2018 statistical update. Washington DC, USA: Communications Development Incorporated; 2018. Available from: http://www.hdr.undp.org/en/content/humandevelopment-indices-indicators-2018-statistical-update. 